\title{
Die Versuchung des Doktor Claus Selinger
}

\author{
Erhard Taverna
}

Der Wunderheiler Friedrich Meisner: «Diese Verstandesakrobaten, dachte er voller Verachtung, die Konstrukteure ohne jede Vision. Sie glauben, sie könnten eine Welt auf der Vernunft aufbauen, hatte er damals gedacht, und das, obwohl alles eigentlich unvernünftig ist. Er mochte es gern, an den «tiefsten Sinn aller Dinge> zu denken: Dieser Kern war unerreichbar und deshalb auch unantastbar.» Sein Gegenspieler, der Arzt Claus Selinger: «Und wir, wir vernünftigen Ärzte in Seefond, wir hatten sie alle behandelt. Wir liessen sie zur Ader, setzten Blutegel an, reichten Brechmittel, starke Laxiermittel, Quecksilber bis sie zu speien begannen, gaben ihnen Branntwein, Salmiakspiritus, spanischen Schnupftabak, Zinnober, kalte Bäder, warme Bäder, Schwefelbäder, Salzbäder [...]. Wir taten was wir konnten. Wir lernen immer mehr hinzu, und wir müssen weitermachen. Aber irgendwo ist eine Leere, ein Bedürfnis, das wir nicht erreichen.»

Der schwedische Autor Per Olov Enquist beschreibt in seinem Roman «Der fünfte Winter des Magnetiseurs» einen Mann auf der Flucht, eine schillernde Figur, in deren Leben Aufstieg und Absturz wie die Jahreszeiten folgen. Friedrich Meisner erreicht im Winter 1793 die bayrische Stadt Seefond, wo er die blinde Tochter des Arztes Selinger heilt. Namen, Ereignisse und Orte sind erfunden, doch über weite Strecken dient als Vorlage für den suggestiven Wundertäter die Biographie von Franz Anton Mesmer, dem Erfinder des Magnetismus. Meisner heilt, zum Teil in überfüllten Sälen, viele Patienten, denen die Schulmedizin nicht helfen konnte.

Enquist zieht uns zuerst durch die Sprache in seinen Bann, eine dunkle, konzentrierte, poetische Sprache, bei der es eine Weile dauert, bis die Sätze eine Perspektive in eine schwindelnde Tiefe eröffnen. Allmählich baut er eine Spannung auf, in der die Personen aus dem Wechsel von inneren und äusseren Landschaften fast beängstigend intensiv zu leben beginnen. Enquist steht auf der Seite der Aufklärung, die in jener Zeit mit den Bränden der französischen Revolution das übrige Europa zu erhellen beginnt. Das Licht der Rationalität beleuchtet aber auch die Nacht der menschlichen Seele. Analyse und Ekstase sind nicht zu trennen. Schon gar nicht in der Medizin. Anfänglich erliegt auch Selinger der Macht des Heilers, denn er ist ihm dankbar, bewundert ihn, vergisst seine Langeweile und spürt gleich-

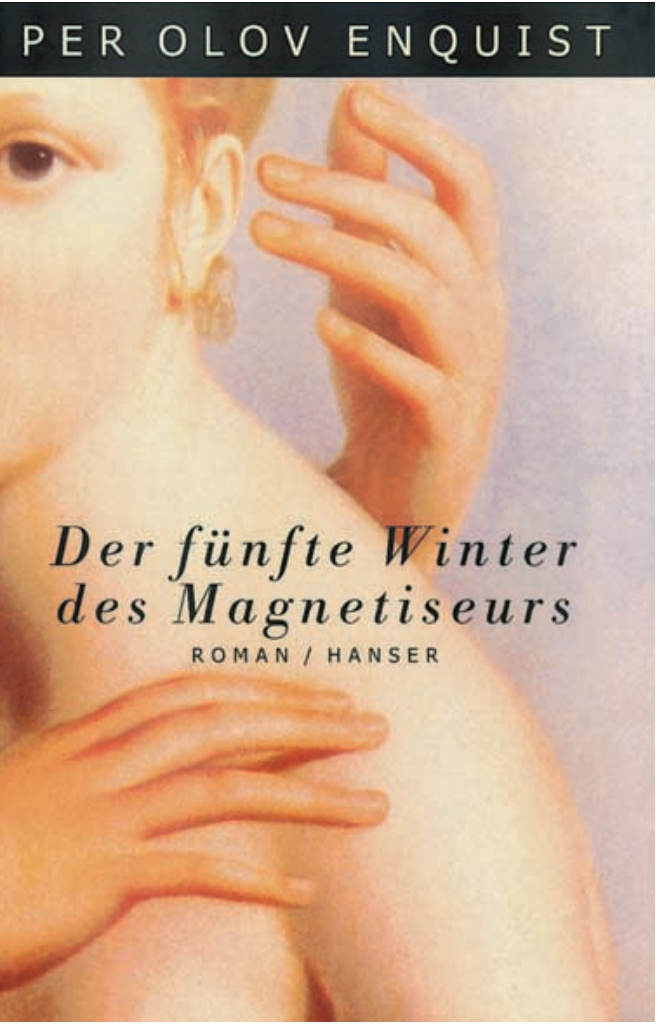

zeitig, wie ihm der bisher sichere Grund entgleitet. Er begleitet ihn als medizinischen Experten und hofft, von dessen Aufstieg als Forscher profitieren zu können. «Ich habe den Beruf des Arztes gewählt», erklärt er einmal seiner geheilten Tochter, «weil ich nicht glaube, dass das Tierische und Dunkle die Macht übernehmen darf, auch wenn es uns ein Glücksgefühl vermittelt. Der Verrat ist eine schöne Kunst, aber nur in kleinen Portionen.» An diesen Portionen scheitert Meisner, der regelmässig an den Verführungen seiner eigenen Macht scheitert. Er, der «einen Hebel unter die Häuser dieser Welt gesetzt hat», wird am Ende von jenen am schlimmsten gehasst, die ihm am meisten verfallen waren.

Per Olov Enquist hat seinen Roman schon einmal 1964 erzählt. Vielleicht hat der Verlag den damaligen Erstling nur deshalb neu aufgelegt, weil er den Erfolg des vorausgehenden Romans «Der Besuch des Leibarztes» ausnützen möchte. Vielleicht. Es kann aber auch sein, dass wir heute für das Thema mehr Gespür entwickelt haben, denn die Geschichte kann auf mehreren Ebenen gelesen werden: als spannende Reportage gegenseitiger Verführungen, als Politparabel 
in Form eines historischen Berichtes über Massensuggestion oder als Exkurs über die Grenzen der Illusion und der Vernunft. Der historische Magnetismus wird heute als Vorläufer der Psychoanalyse gedeutet, als ein Phänomen, in dem sich die Entdeckung des Unbewussten ankündete. Peter Sloterdijk hatte, rund 20 Jahre nach Enquist, eine Expedition in das untergegangene Reich der Magnetiseure gewagt. In seinem Buch «Der Zauberbaum» schildert er die belegten Therapieexperimente des Marquis und Mesmerschülers Puységur, den er sagen lässt: «Die Zauberformel heisst: allez - touchez - guérissez! In diesen drei Worten liegt das ganze Geheimnis der magnetischen Praxis.» Nach einem Jahrzehnt verstärkter Gehirnforschung sind wir empfänglicher für die verschlungenen Irrungen und Wirrungen einer Wissenschaftsgeschichte, die im nachhinein eine kausale Ordnung konstruiert, die von Mesmers Hypnoseséancen in Wien und
Paris, über die Pioniere der Neurophysiologie des folgenden 19. Jahrhunderts, wieder zurück nach Wien zu Freud und nach ihm bei der modernen Dissoziationsforschung und den aktuellen Methoden der funktionellen Kernspintomographie vorläufig endet.

Noch einmal Selinger, der wie Judas den Meister verrät, weil er die redliche Niederlage dem sieghaften Rausch vorzieht: «Wir sollten ein Urteil fällen, das zum Ausdruck bringt, dass wir uns von ihm distanzieren. Aber wir erreichen nicht das, was hinter ihm steht; der Gestalt, die wir hinter Meisner schemenhaft hervortreten sehen, ist mit einem einfachen Gerichtsverfahren nicht beizukommen. Sie ist unsichtbar.» Sie ist ein Teil von uns selber, würden wir heute sagen.

Per Olov Enquist:

Der fünfte Winter des Magnetiseurs.

München: Hanser; 2002. ISBN 3-446-20129-7. 